UHERO

THE ECONOMIC RESEARCH ORGANIZATION AT THE UNIVERSITY OF HAWAIII
INCENTIVIZING INTERDEPENDENT RESOURCE MANAGEMENT: WATERSHEDS, GROUNDWATER, AND COASTAL ECOLOGY

BY

KIMBERLY BURNETT, JAMES A. ROUMASSET, SITTIDAJ PONGKIJVORASIN \& CHRISTOPHER A. WADA

Working Paper No. 2014-9

June 2014 


\title{
Incentivizing interdependent resource management: watersheds, groundwater, and coastal ecology
}

\section{Kimberly Burnett, James Roumasset, Sittidaj Pongkijvorasin, Christopher A. Wada}

\begin{abstract}
Managing water resources independently may result in substantial economic losses when those resources are interdependent with each other and with other environmental resources. We first develop general principles for using resources with spillovers, including corrective taxes (subsidies) for incentivizing private resource users. We then analyze specific cases of managing water resources, in particular the interaction of groundwater with upstream or downstream resource systems.
\end{abstract}




\section{Introduction}

Managing a single water resource typically requires an understanding of the linkages between key hydrologic factors and direct human influences (Qureshi et al., 2012). The problem is further complicated by the fact that water resources are often interdependent, which suggests that management should also account for ecological interlinkages. For example, a forested upstream watershed may replenish an underlying groundwater aquifer, or a coastal groundwater aquifer may provide positive spillover effects to a downstream nearshore resource such as a fishery. Left unregulated, these spillover effects are economic externalities. In general when private parties act in their self-interest in the presence of externalities, the outcome is not socially optimal.

Economic theory provides tools for aligning private incentives with the social optimum: taxes and payments. These tools can be applied directly to resource management problems, wherein the spillover effect is direct and transient (e.g. air pollution from oil and coal) or direct and dynamic (e.g. downstream sedimentation resulting from logging). The theory is less complete, however, when externalities are indirect, as they often are for water resources (e.g. the stock of coastal groundwater enhancing the stock of a nearshore aquatic species via submarine groundwater discharge). We therefore begin this chapter by extending the theory of externalities to include both static and dynamic indirect externalities and provide a taxonomy of externalities arising from resource use.

For direct water or other resource externalities, optimal resource use can be incentivized by setting the price equal to the sum of marginal extraction cost, marginal user cost, and marginal externality cost. In contrast, we find that indirect resource externalities do not generate a separable marginal externality cost, even though the efficiency price can be separated into three distinct terms. This has important implications for calculating corrective taxes or payments. In 
particular, setting a tax equal to the marginal externality cost for direct externalities is sufficient to align private incentives with the social optimum, whereas the shadow price of pollution for indirect externalities is not clearly defined and requires a more complex optimal dynamic tax formula.

\section{A taxonomy of externalities arising from resource use}

When resource use creates a direct downstream externality, the marginal opportunity cost (MOC) of using the resource consists of three components: marginal extraction cost (c), marginal user cost (MUC), and marginal externality cost (MEC). MUC is the present value of the resource stock forgone at the time that a unit of the resource is extracted, or equivalently, the cost associated with having one unit less of the resource available in the future. ${ }^{1}$ In the case of an aquifer, for example, the MUC of pumping a unit of groundwater today includes the effect on future extraction costs and prices. MEC refers to the downstream, external cost (e.g. pollution) caused by extracting a unit of the resource. The efficient level of resource use can be specified by equating the marginal benefit $(\mathrm{MB})$ of resource extraction with the $\mathrm{MOC}$, i.e. $M B=c+M U C+$ MEC (Pearce and Turner, 1989). This simple rule has many applications. If there are no externalities, efficient extraction requires that the MB in each period equals the sum of unit extraction cost and marginal user cost - the standard dynamic optimality condition in resource economics. If instead resource management is considered in a static setting (such that $M U C=0$ ),

\footnotetext{
${ }^{1}$ We assume that the costs, benefits, and resource characteristics in this chapter are known with certainty, i.e. the developed model is deterministic. In the presence of uncertainty, the objective of the management problem would need to be adjusted to maximize the expected net present value of the resource(s), but the resource externality taxonomy developed in this section would still apply.
} 
optimality requires that the MB of the resource is equal to its marginal extraction cost plus MEC, the latter of which is sometimes referred to as the marginal damage cost. Thus the MOC extraction rule, first introduced by Pearce and Markandya (1989), potentially unifies resource and environmental economics. When the externality is indirect (as explained below), however, it turns out that the standard Pearce equation does not apply.

Externalities can be classified according to durability of damages (stock or flow) and pathway (direct or indirect). The top row in Table 1 illustrates the two most analyzed cases. Pigou's (1920) canonical flow pollution is represented in the first cell. In the context of water, sending dam water through hydroelectric generators on the way to farms for agricultural irrigation results in a positive spillover in the form of electricity generation. Global warming, a standard stock externality, is represented in the second cell (first row, second column), wherein extracting and burning fossil fuels generates a stock effect whereby the accumulation of carbon in the atmosphere exacerbates climate change (Nordhaus, 1991; Sinclair, 1994; Ulph and Ulph, 1994; Hoel and Kverndokk, 1996; Farzin and Tahvonen, 1996). Similarly, agricultural irrigation over an underlying aquifer can generate a stock effect if salts and agricultural chemicals leach into any excess applied water that eventually recharges the aquifer (Tsur, 1991; Knapp and Baerenklau, 2006). When the pathway is direct, i.e. extraction directly generates the externality, the "Pearce equation" $(M B=c+M U C+M E C)$ is applicable to both stock and flow externalities.

In contrast, the second row in Table 1 characterizes externalities that exhibit indirect pathways. When damages are transient, e.g. a reduction of forest amenities resulting from a harvesting-induced decline in the stock of a forest (Berck, 1981; Krautkraemer, 1985), the externality is categorized as stock-to-flow (second row, first column). Stock-to-flow externalities can also be positive, as is the case when water in a reservoir provides scenic value. When on the 
other hand damages are dynamic, i.e. changes in the harvested resource stock affects a second stock, the externality is classified as stock-to-stock (second row, second column). Despite an abundance of stock-to-stock externality examples in the literature - e.g. deforestation causing downstream sedimentation (Dixon, 1997; Magrath and Doolette, 1990), predator-prey interactions (Settle and Shogren, 2002; Settle et al., 2002), coastal aquifer levels affecting nearshore marine ecology through submarine groundwater discharge (Pongkijvorasin et al., 2010), differing levels of adjacent aquifers resulting in water quality degradation due to discharge from one water body to the other (Zeitouni and Dinar, 1997), and intrusion of saline water into coastal aquifers due to overpumping (Tsur and Zemel, 1995; Moreaux and Reynaud, 2004; Reinelt, 2005) - there is some uncertainty regarding how to internalize such externalities for optimal conservation and harvesting over time.

Table 1. Classification of resource-extraction externalities

\begin{tabular}{|l|l|l|}
\hline \multirow{2}{*}{ Pathway } & \multicolumn{1}{|c|}{ Durability of damages } \\
\cline { 2 - 3 } & Transient, one-period & Synamic \\
\hline Flow externality & $\begin{array}{l}\text { Soot and acid rain from coal; } \\
\text { Hydroelectricity generation from dam } \\
\text { irrigation water }\end{array}$ & $\begin{array}{l}\text { Greenhouse gases; } \\
\text { Logging creates erosion which leads to } \\
\text { sedimentation of downstream dams or } \\
\text { coral reefs; } \\
\text { Indigation reduces the quality of underlying } \\
\text { groundwater }\end{array}$ \\
& $\begin{array}{l}\text { Stock-to-flow externality } \\
\text { Resource-amenity values e.g. beautiful } \\
\text { forests or water reservoirs }\end{array}$ & $\begin{array}{l}\text { Stock-to-stock externality } \\
\text { Predator-prey effects; } \\
\text { Watershed quality affecting downstream- } \\
\text { sedimentation; } \\
\text { Coastal aquifer levels affecting nearshore } \\
\text { marine resources; } \\
\text { Wetland development generating marine } \\
\text { pollution } \\
\text { Seawater intrusion of a coastal aquifer }\end{array}$ \\
\hline
\end{tabular}


Direct flow and stock externalities can be corrected by taxing resource extraction by an amount equal to the MEC. This type of Pigouvian tax incentivizes socially optimal extraction of the resource by requiring the resource user to account for the contemporaneous marginal damage costs generated by his extraction decisions. In these particular cases, the MUC and MEC are additively separable. We show below, however, that when the pathway is indirect, the MEC is not additively separable because accumulation today has welfare implications for the future. Instead, the spillover effects of resource use are included in the marginal user cost such that the shadow price of pollution is not clearly defined. In the remainder of this chapter, we derive corrective taxation and pricing of a resource for this case, using the example of a watershedaquifer-coastal ecosystem.

\section{General renewable resource model}

We begin by constructing a fairly general framework for renewable resource management, which includes all four externality types characterized in Table 1 . While we do not know of an example where all four types are simultaneously present, writing the model in this way avoids separately writing the model for all four cases. Suppose that a resource stock $X$ (e.g. an aquifer) is extracted at rate $x$ generating a contemporaneous marginal benefit $p(x)$ at a cost of $c(X)$ per unit. The cost of extraction is assumed to be a decreasing and convex function of the resource stock, i.e. $c^{\prime}(X)<0$, and $c^{\prime \prime}(X) \geq 0$. In the case of groundwater, the marginal pumping cost increases as the stock of the aquifer declines because water must be lifted a longer distance to the surface. The stock changes over time according to the strictly concave natural growth function $f(X)$ where $X_{\min } \leq X \leq X_{\max }$-minus resource extraction. For a groundwater aquifer, the growth function would be the difference between natural recharge into the system from precipitation and 
adjacent water bodies and discharge out of the systems (e.g. to the ocean). Resource use may also generate a flow externality, captured by the increasing and convex function $D(x)$, and, by virtue of decreasing the stock, decrease the indirect stock-to-flow amenity benefit, $B(X)$. Supposing that the resource is water stored in a reservoir, using the water for irrigation generates a positive flow externality if the water is first passed through hydroelectric generators, but reducing the stock concurrently reduces the stock-to-flow scenic value provided by the reservoir. Extraction of $X$ may also have a direct effect on a downstream stock $G$ according to the function $g(x)$, resulting in damages captured by the convex damage function $I(G)$. When the downstream stock is a pollutant (e.g. agricultural chemicals leaching into groundwater as a result of irrigation), the model should also allow for dissipation (here modeled as a constant rate $\beta$ ). Finally, extraction may generate an indirect stock-to-stock externality. For example, decreasing land cover $(X)$ on a watershed increases the stock of sediments $(S)$ on a coral reef causing damages represented by the convex damage function $E(S)$. The effect of the upstream stock on the downstream stock is represented by the function $h(X)$, and $S$ dissipates at a constant rate $\delta$.

Given a positive discount rate $r$, the dynamic resource management problem is to choose the extraction path that maximizes the present value of net social benefit, i.e.

$$
\begin{aligned}
\max _{x \geq 0} \quad V & =\int_{0}^{\infty} e^{-r t}\left[\int_{0}^{x_{t}} p(z) d z-c\left(X_{t}\right) x_{t}-D\left(x_{t}\right)+B\left(X_{t}\right)-I\left(G_{t}\right)-E\left(S_{t}\right)\right] d t \\
\text { s.t. } \quad \dot{X}_{t} & =f\left(X_{t}\right)-x_{t} \\
\dot{S}_{t} & =h\left(X_{t}\right)-\delta S_{t} \\
\dot{G}_{t} & =g\left(x_{t}\right)-\beta G_{t}
\end{aligned}
$$

Using the first order conditions for the optimal control problem (1), one can derive optimal resource extraction conditions for each of the four types of externalities (Table 2). The co-state variables $\lambda, \alpha$, and $\theta$ correspond to the state equations for $X, S$, and $G$ respectively. In the case of 
externalities resulting directly from resource use (top row), the optimality conditions require that $p=c+M U C+M E C$. For direct and transient externalities, the MEC is equal to the marginal damage cost, $D^{\prime}(x)$, or the damage generated immediately by resource extraction. For direct and dynamic externalities, the MEC is equal to the shadow price $-\theta$ and therefore represents the present value cost of adding one more unit to the pollution stock $G$, given the dissipation rate $\beta$.

In keeping with the standard paradigm for internalizing externalities, we initially assume that resource users are private entities and ask what corrective taxes (or subsidies) are needed for rational decision makers to choose the optimal level of resource use. It is tempting to conclude that each of the three additively separable terms in the MOC for stock-to-flow and stock-to-stock externalities (bottom row of Table 2) similarly correspond to c, MUC, and MEC. Careful examination of the optimality conditions reveals that this is not the case, however. Rather the MEC term is not defined, and $p=c+M U C$ along the optimal path. That is, the external costs generated by resource use are captured entirely in the marginal user cost term. Thus setting a tax equal to $B^{\prime}(x) /\left[r-f^{\prime}(X)\right]$ in order to internalize a stock-to-flow externality, for example, would not incentivize optimal resource extraction.

Table 3 characterizes the corrective taxes for a private owner for each of the four types of externalities. ${ }^{2}$ For direct externalities, a private owner can be incentivized to extract at the socially optimal level if the tax is set equal to the MEC. Because the planner must take into account the effect of the tax on future prices, the optimal corrective tax for an indirect externality is not exactly equal to MEC or MUC. Moreover, the optimal tax is dynamic and may be increasing or decreasing over time, depending on how the stock of the externality-generating resource is changing over time. One can show that the optimal stock-to-stock externality tax is

\footnotetext{
${ }^{2}$ Succinct mathematical derivations can be found in the appendix of this chapter.
} 
decreasing in the resource stock and increasing in the downstream stock, i.e. $\partial T / \partial X<0$, and $\partial T / \partial S>0$.

Table 2. Optimal conditions for resource-extraction externalities

\begin{tabular}{|c|c|c|}
\hline \multirow[t]{2}{*}{ Pathway } & \multicolumn{2}{|c|}{ Durability of damages } \\
\hline & Transient, one-period & Dynamic \\
\hline$p=c+M U C+M E C$ & $\begin{array}{l}\text { Flow externality } \\
p(x)=c(X)+\lambda+D^{\prime}(x) \text { and } \\
\lambda=\frac{\dot{p}-c^{\prime}(X) f(X)}{r-f^{\prime}(X)}\end{array}$ & $\begin{array}{l}\text { Stock externality } \\
p(x)=c(X)+\lambda-\theta \text { and } \\
\lambda=\frac{\dot{p}-c^{\prime}(X) f(X)}{r-f^{\prime}(X)}+\frac{r \theta+\beta \theta+I^{\prime}(G)}{r-f^{\prime}(X)}\end{array}$ \\
\hline $\begin{array}{l}\text { Indirect } \\
p=c+M U C\end{array}$ & $\begin{array}{l}\text { Stock-to-flow externality } \\
p(x)=c(X)+\lambda \text { and } \\
\lambda=\frac{\dot{p}-c^{\prime}(X) f(X)}{r-f^{\prime}(X)}+\frac{B^{\prime}(x)}{r-f^{\prime}(X)}\end{array}$ & $\begin{array}{l}\text { Stock-to-stock externality } \\
\begin{array}{l}p(x)=c(X)+\lambda \text { and } \\
\lambda=\frac{\dot{p}-c^{\prime}(X) f(X)}{r-f^{\prime}(X)}+\frac{\alpha h^{\prime}(X)}{r-f^{\prime}(X)}\end{array}\end{array}$ \\
\hline
\end{tabular}

Table 3. Corrective taxes for resource-extraction externalities

\begin{tabular}{|l|l|l|}
\hline \multirow{2}{*}{ Pathway } & \multicolumn{2}{|c|}{ Durability of damages } \\
\cline { 2 - 3 } Daxect $=M E C$ & Transient, one-period & Dynamic \\
\hline Indirect & $T_{t}=D^{\prime}(x)$ & $T_{t}=-\theta$ \\
Tax $\neq M E C$ & Stock-to-flow externality & Stock-to-stock externality \\
& $T_{t}=\int_{t}^{\infty} B^{\prime}(x) e^{-\int_{t}^{\tau}\left(r-f^{\prime}(X)\right) d v} d \tau$ & $T_{t}=\int_{t}^{\infty} \alpha h^{\prime}(X) e^{-\int_{t}^{\left(r-f^{\prime}(X)\right) d v} d \tau}$ \\
& & \\
\hline
\end{tabular}


Because a private owner will account for the marginal extraction cost when maximizing his individual benefit, the corrective tax need only be set as in Table 3 to internalize the spillover effect. If the resource is instead controlled by a public utility the marginal consumer price should be determined by the Pearce equation, i.e. set equal to $\mathrm{c}+\mathrm{MUC}+\mathrm{MEC}$ for direct externalities and equal to $\mathrm{c}+\mathrm{MUC}$ (which includes the spillover effect) for indirect externalities.

\section{Watersheds, aquifers, and coastal ecology}

Given the interconnected nature of water resources, various types of externalities often arise when considering optimal water management. For example, agricultural irrigation often generates a stock externality when pesticides or fertilizers leach into water that recharges an underlying aquifer. Stock and stock-to-flow externalities may be generated by a variety of upstream watershed management activities. In addition to increasing downstream groundwater recharge, watershed conservation - which may include reduced logging - lessens sedimentation in downstream reservoirs (stock externality) and increases the amenity values of the forest (stock-to-flow externality). We pay particular attention to the example of a coastal groundwater aquifer and a keystone algal species in the nearshore environment (stock-to-stock externality). ${ }^{3}$

When the stock of freshwater in an underground coastal aquifer declines due to forces such as climate change or increased pumping, so does the amount of groundwater that discharges at the coast. This reduction in submarine groundwater discharge (SGD), in turn, affects nearshore seawater quality and marine ecosystems via changes in nutrient loads, temperature, and salinity. Such disturbances may endanger marine plant and animal species with ecological, cultural,

\footnotetext{
${ }^{3}$ This section follows Pongkijvorasin et al. (2010).
} 
and/or economic value. For example, it has been shown that moderate levels of SGD influx to a coastal marine environment may increase the growth rate of Gracilaria coronopifolio (henceforth "limu"). A lower groundwater stock thus results in less SGD and lower rates of limu growth (Duarte et al., 2010). Inasmuch as limu is often regarded as a keystone species of reef ecology in Hawaii, withdrawing groundwater may exert a significant negative externality on the environment. Because groundwater pumping affects the nearshore environment indirectly by reducing the stock of freshwater stored in the coastal aquifer, it falls into the stock-to-stock externality category from tables 1-3.

Suppose that the state of the upstream resource, in this case groundwater, changes over time according to the following equation of motion:

$$
\dot{h}_{t}=a\left[R-l\left(h_{t}\right)-q_{t}\right]
$$

where $h$ is the aquifer head level, $a$ is a volume-to-height conversion factor, $R$ is natural recharge to the aquifer, $l$ is head-dependent discharge to the ocean or SGD, and $q$ is extraction. Suppose also that the state equation for the downstream resource, limu, is described as follows:

$$
\dot{S}_{t}=g\left(S_{t}, h_{t}\right)-m_{t}
$$

where $S$ is the stock of limu, $g$ is the growth function which depends on both the groundwater and limu stock, and $m$ is limu harvest. Maximizing net social benefits requires that the following condition is satisfied:

$$
p=c(h)+\frac{\dot{p}-a c^{\prime}(h)(R-l(h))}{r+a l^{\prime}(h)}+\frac{\theta a g_{h}(S, h)}{r+a l^{\prime}(h)}
$$

where $\theta$ is the costate variable corresponding to Eq. 3. Upon careful inspection, Eq. 4 corresponds exactly to the optimality condition in the bottom row and second column of Table 2 as expected. 


\section{Application to the Kukio region in Hawaii}

Using data collected from the Kukio region on the North Kona coast of Hawaii Island, Pongkijvorasin et al. (2010) show that optimal water management before accounting for the externality involves slightly higher extraction rates. In this particular example, the market value of algae is relatively small compared to the benefit of water consumption. If the benefit function were modified to include the ecological and cultural value of limu, one might expect the difference in extraction rates to be more substantial. Reduced groundwater pumping would allow the aquifer head to follow a higher trajectory, resulting in increased flows of beneficial SGD to the nearshore. Because ecological and cultural values are difficult to measure, Pongkijvorasin et al. (2010) instead impose minimum algae stock constraints to account for the stock-to-stock externality. When the current algae stock is constrained to be no less than $90 \%$ of its current level, optimal water extraction falls dramatically from roughly 6 million $\mathrm{m}^{3}$ per year in the market value case to 3 million $\mathrm{m}^{3}$ annually by year ten and less than 0.5 million $\mathrm{m}^{3}$ per year from year 22 onward.

The optimal corrective tax in this context is given by the following:

$$
T_{t}=\int_{t}^{\infty} \theta g_{h}(S, h) e^{-\int_{t}^{\tau}\left(r+a l^{\prime}(h)\right) d v} d \tau
$$

All else equal, if the aquifer head level is lower, the tax should be higher to slow pumping and capture the positive spillover effect. If the stock of limu is lower ceteris paribus, the tax should also be lower because the resource benefiting from the positive spillover is smaller. In general, either effect may dominate at any point in time, depending on the particular characteristics of the problem under consideration. In this example, the optimal tax is likely to be very small because the market for limu is small relative to that for groundwater and groundwater is relatively 
abundant. Numerical applications of this theory could further illuminate how large, small, and changing spillover effects might affect optimal water-resource management.

\section{Conclusions}

We present a taxonomy of externalities arising from resource use, with an emphasis on water resources. The general model is applicable within a static, dynamic, direct and indirect framework. We provide optimal pricing conditions under each type of externality, as well as corrective taxes for incentivizing proper use of the resource. While optimal extraction and consumption can be incentivized using a traditional Pigouvian tax - i.e. charging the shadow price of pollution (equal to the marginal externality cost) - in the case of direct flow and stock externalities, the MEC is undefined for externalities with an indirect pathway. Because accumulation today has welfare implications for the future, taxing resource extraction according to the shadow price of pollution in those cases will not yield an optimal outcome. Instead, the closed formed solution for an optimal indirect externality tax is determined by solving a modified version of the original dynamic optimization problem.

While flow (e.g., pollution) and stock (e.g., greenhouse gases) externality management models have been well developed in the literature, less progress has been made in stock-to-flow (amenity values) and stock-to-stock (linked marine systems) frameworks. We provide an example of appropriate stock-to-stock resource management in a linked marine ecology-coastal groundwater aquifer setting. When the downstream resource provides relatively little market value and quantifying non-extractive values is difficult, we find that management of the primary resource remains largely unaffected. When a stock constraint is imposed to ensure a minimum level of ecological and cultural ecosystem services, however, the effect on optimal extraction is 
dramatic. In our example, a 90\% minimum algae stock constraint in the nearshore environment results in a 50\% reduction in optimal upstream groundwater extraction in the short term and an even larger proportional reduction in the longer term. In general, ignoring a positive (negative) stock-to-stock externality when managing a resource leads to over- (under-) extraction.

Capturing relevant hydrological, economic, and ecological linkages in pairwise spillover relationships is already a challenge, but one can imagine extending the framework to multiple actors and water resources. For example, consider a watershed-aquifer-nearshore system, wherein land in the upstream watershed is privately owned, a water authority regulates groundwater use midstream, and the downstream benefit to nearshore ecology (e.g. reef quality) is viewed as a public good. Because the watershed recharges the midstream aquifer, landowners can be incentivized to participate in conservation to enhance recharge through payments for watershed services, which will depend on, among other things, the shadow price of groundwater. Because the downstream marine ecosystem only receives but does not generate a spillover, its price need not be adjusted; optimality can be achieved by charging the usual extraction plus marginal user cost. The corrective tax on the groundwater resource will be most complex because the marginal user cost of water will depend on both the upstream watershed quality and the spillover effect on the nearshore ecosystem.

These models advance sustainability science by providing a mechanism to examine optimal resource management within a framework of linked natural systems. However more work needs to be done to increase understanding of and to quantify those linkages, as well as to improve methods for valuing non-extractive services provided by different types of ecosystems. 


\section{References}

Berck, P. (1981), 'Optimal Management of Renewable Resources with Growing Demand and Stock Externalities', Journal of Environmental Economics and Management, 8, 105-117.

Dixon, J. (1997), ‘Analysis and Management of Watershed', in P. Dasgupta and K.G. Maler (eds), The Environment and Emerging Development Issues, vol. 2, Oxford: Clarendon Press.

Duarte, T.K., Pongkijvorasin, S., Roumasset, J., Amato, D. and K. Burnett (2010), 'Optimal management of a Hawaiian Coastal aquifer with nearshore marine ecological interactions', Water Resources Research, 46, W11545.

Farzin, Y. H. and O. Tahvonen (1996), 'The global carbon cycle and the optimal time path of a carbon tax', Oxford Economic Papers, 48, 515-536.

Hoel, M. and S. Kverndokk (1996), 'Depletion of fossil fuels and the impacts of global warming', Resource and Energy Economics, 18, 115-136.

Knapp, K.C. and K.A. Baerenklau (2006), 'Ground Water Quantity and Quality Management: Agricultural Production and Aquifer Salinization over Long Time Scales', Journal of Agricultural and Resource Economics, 31, 616-641.

Krautkramer, J. (1985), 'Optimal growth, resource amenities and the preservation of natural environment', Review of Economic Studies, 52, 161-81.

Magrath, W. B. and J.B. Doolette (1990), 'Strategic Issues in Watershed Development', in W.B. Magrath and J.B. Doolette (eds), Watershed Development in Asia: Strategies and Technologies, Washington DC: World Bank.

Moreaux, M. and A. Reynaud (2004), 'Optimal joint management of a coastal aquifer and a substitute resource', Water Resources Research, 40, W06S18. 
Nordhaus, W.D. (1991), 'To Slow or Not to Slow: The Economics of the Greenhouse Effect', The Economic Journal, 101 (407), 920-937.

Pearce, D. and A. Markandya (1989), 'Marginal opportunity cost as a planning concept', in G. Schramm and J.J. Warford (eds), Environmental Management and Economic Development, Baltimore: The Johns Hopkins University Press.

Pearce, D. and K. Turner (1989), Economics of Natural Resources and the Environment, Baltimore: The Johns Hopkins University Press.

Pigou, A.C. (1920), The Economics of Welfare, London: Macmillan.

Pongkijvorasin, S., J. Roumasset, T.K. Duarte and K. Burnett (2010), 'Renewable resource management with stock externalities: Coastal aquifers and submarine groundwater discharge', Resource and Energy Economics, 32, 277-291.

Qureshi, M.E., A. Reeson, P. Reinelt, N. Brozovic and S. Whitten (2012), 'Factors determining the economic value of groundwater', Hydrogeology Journal, 20, 821-829.

Reinelt, P. (2005), 'Seawater intrusion policy analysis with a numerical spatially heterogeneous dynamic optimization model', Water Resources Research, 41, W05006.

Settle, C. and J.F. Shogren (2002), 'Modeling Native-Exotic Species within Yellowstone Lake', American Journal of Agricultural Economics, 84 (5), 1323-1328.

Settle, C., T.D. Crocker and J.F. Shogren (2002), 'On the joint determination of biological and economic systems', Ecological Economics, 42, 301-311.

Sinclair, P.J. (1994), 'On the trend of fossil fuel taxation', Oxford Economic Papers, 46, 869877. 
Tsur, Y. (1991), 'Managing Drainage Problems in a Conjunctive Ground and Surface Water System', in A. Dinar and D. Zilberman (eds), The Economics and Management of Water and Drainage in Agriculture, Boston: Kluwer Academic Publishers.

Tsur, Y. and A. Zemel (1995), 'Uncertainty and irreversibility in groundwater resource management', Journal of Environmental Economics and Management, 29, 149-161.

Ulph, A. and D. Ulph (1994), 'The optimal time path of a carbon tax', Oxford Economic Papers, 46, 857-868.

Zeitouni, N. and A. Dinar (1997), 'Mitigating Negative Water Quality and Quality Externalities by Joint Management of Adjacent Aquifers,' Environmental and Resource Economics, 9, $1-20$.

\section{Appendix}

\section{Flow externality}

In the case of a flow externality, the general optimization problem (1) is reduced to the following:

$$
\begin{array}{rlrl}
\max _{x \geq 0} & V=\int_{0}^{\infty} e^{-r t}\left[\int_{0}^{x_{t}} p(z) d z-c\left(X_{t}\right) x_{t}-D\left(x_{t}\right)\right] d t \\
\text { s.t. } & \dot{X}_{t}=f\left(X_{t}\right)-x_{t}
\end{array}
$$

The necessary conditions can be combined to derive an efficiency price condition:

$$
\begin{aligned}
& p(x)=c(X)+\lambda+D^{\prime}(x) \\
& p(x)=c(X)+\frac{\dot{p}-c^{\prime}(X) f(X)}{r-f^{\prime}(X)}+D^{\prime}(x)
\end{aligned}
$$

Given that the costate variable $\lambda$ is the MUC by definition, it follows that the MEC is equal to $D^{\prime}(x)$, and the externality can be internalized by setting a tax equal to the MEC. 


\section{Stock externality}

When the externality is direct but dynamic rather than transient, i.e. a stock externality, the optimization problem becomes

$$
\begin{array}{ll}
\max _{x \geq 0} & V=\int_{0}^{\infty} e^{-r t}\left[\int_{0}^{x_{t}} p(z) d z-c\left(X_{t}\right) x_{t}-I\left(G_{t}\right)\right] d t \\
\text { s.t. } & \dot{X}_{t}=f\left(X_{t}\right)-x_{t} \\
& \dot{G}_{t}=g\left(x_{t}\right)-\beta G_{t}
\end{array}
$$

and the following efficiency price condition can be derived from the first order conditions:

$$
\begin{aligned}
& p(x)=c(X)+\lambda-\theta \\
& p(x)=c(X)+\frac{\dot{p}-c^{\prime}(X) f(X)}{r-f^{\prime}(X)}+\frac{\theta \beta+\theta r+I^{\prime}(G)}{r-f^{\prime}(X)}-\theta \\
& p(x)=c(X)+\frac{\dot{p}-c^{\prime}(X) f(X)}{r-f^{\prime}(X)}+\frac{\theta \beta+\theta f^{\prime}(X)+I^{\prime}(G)}{r-f^{\prime}(X)}
\end{aligned}
$$

Because $\theta$ is the costate variable associated with the stock $G$, it can be interpreted as the incremental contribution to present value of an additional unit of $G$. Since the value of pollution is negative, $\theta$ is also negative, and a tax equal to $-\theta$ will internalize the stock externality, i.e. restore efficiency.

\section{Stock-to-flow externality}

Stock-to-flow externalities are indirect and transient. The optimization problem for a stock-toflow externality is

$$
\begin{array}{ll}
\max _{x \geq 0} & V=\int_{0}^{\infty} e^{-r t}\left[\int_{0}^{x_{t}} p(z) d z-c\left(X_{t}\right) x_{t}+B\left(X_{t}\right)\right] d t \\
\text { s.t. } & \dot{X}_{t}=f\left(X_{t}\right)-x_{t}
\end{array}
$$

The necessary conditions for (A5) can be rearranged in the following manner: 


$$
\begin{aligned}
& p(x)=c(X)+\lambda \\
& p=c(X)+\frac{\dot{p}-c^{\prime}(X) f(X)}{r-f^{\prime}(X)}+\frac{B^{\prime}(X)}{r-f^{\prime}(X)}
\end{aligned}
$$

It is tempting to conclude that the third term on the right hand side of (A6) is the MEC, as in the flow externality case. Upon further examination of (A6), however, one can see that the shadow price or MUC $\lambda$, includes all terms other than the marginal extraction cost. That is, the externality effect is embedded within the MUC and is not additively separable. Therefore, the externality will not be internalized by setting a tax equal to $B^{\prime}(X) /\left[r-f^{\prime}(X)\right]$. The proper corrective tax is determined by solving the following problem:

$$
\begin{array}{ll}
\max _{x \geq 0} & \int_{0}^{\infty} e^{-r t}\left[\int_{0}^{x_{t}}(p(z)-T) d z-c\left(X_{t}\right) x_{t}\right] d t \\
\text { s.t. } & \dot{X}_{t}=f\left(X_{t}\right)-x_{t}
\end{array}
$$

which results in the following optimality condition:

$$
p=c(X)+\frac{\dot{p}-c^{\prime}(X) f(X)}{r-f^{\prime}(X)}+\left[T-\frac{\dot{T}}{r-f^{\prime}(X)}\right]
$$

The socially optimal condition (A6) is therefore achieved by choosing a tax $T$ to satisfy

$$
T-\frac{\dot{T}}{r-f^{\prime}(X)}=\frac{B(X)}{r-f^{\prime}(X)}
$$

Solving (A9) with the transversality condition $\lim _{t \rightarrow \infty} e^{-r t} \lambda_{t} X_{t}=0$ yields

$$
T=\int_{t}^{\infty} B^{\prime}(X) e^{-\int_{t}^{\tau}\left(r-f^{\prime}(X)\right) d v} d \tau
$$

\section{Stock-to-stock externality}

When the externality is indirect and dynamic, the optimization problem includes two state variables: 


$$
\begin{array}{ll}
\max _{x \geq 0} & V=\int_{0}^{\infty} e^{-r t}\left[\int_{0}^{x_{t}} p(z) d z-c\left(X_{t}\right) x_{t}-E\left(S_{t}\right)\right] d t \\
\text { s.t. } & \dot{X}_{t}=f\left(X_{t}\right)-x_{t} \\
& \dot{S}_{t}=h\left(X_{t}\right)-\delta S_{t}
\end{array}
$$

Rearranging the necessary conditions results in the following:

$$
\begin{aligned}
& p(x)=c(X)+\lambda \\
& p=c(X)+\frac{\dot{p}-c^{\prime}(X) f(X)}{r-f^{\prime}(X)}+\frac{\alpha h^{\prime}(X)}{r-f^{\prime}(X)}
\end{aligned}
$$

where $\alpha$ is the costate variable corresponding to $S$. Like in the stock-to-flow case, the externality effect is embedded in the MUC and the MEC is undefined. The optimal tax condition can be derived in an analogous manner to (A9), and the result is

$$
T-\frac{\dot{T}}{r-f^{\prime}(X)}=\frac{\alpha h^{\prime}(X)}{r-f^{\prime}(X)}
$$

Using the transversality condition $\lim _{t \rightarrow \infty} e^{-r t} \lambda_{t} X_{t}=0$, equation (A13) can be solved for the closedform optimal tax:

$$
T=\int_{t}^{\infty} \alpha h^{\prime}(X) e^{-\int_{t}^{\tau}\left(r-f^{\prime}(X)\right) d v} d \tau
$$

